To the Editor:

Dear Sir,

\title{
SHOULDER STRENGTHENING EXERCISES
}

First of all, may I apologise to. Messrs Thompson and Morris for any offence which my reply on the two issues of trampoline injury and neck injury during a back rocking exercise. No offence was intended in my reply. My aim in both cases was to indicate that neither activity should be outlawed because they were badly carried out.

The solution lies in there being a greater awareness of how one teaches any physical activity so that forseeable accidents are avoided. Good safe practices are known to, and followed by, thousands of appropriately trained Physical Education specialists. It would seem to me to be a positive step for all those who apply team exercise regimes to look to such people for advice if such sponsors do not know the issues. In the case of the R.F.U. I feel sure that they would readily advise their clubs on the principles and practices of fitness training.

In the spirit of helpful co-operation, may I now respond specifically to the last paragraph of the "Neck Injury" letter in your last issue of the Journal.

If I were looking for a suppling strengthening activity for the shoulders; rather than risk the consequences of error produced by unstable support, I would sit the two athletes back to back with a finger/wrist grip of hands in an extended arms position and then pursue the rocking movement. The risks of a lateral slip are then reduced.

If I want a little more sense of fun then I would use the exercise as outlined by Messrs. Morris and Thompson but I would reassure myself that the athletes were physically agile and strong and able to provide and maintain for themselves stable foot and body positions. This would mean that the coach must establish that the athletes are aware of and practised in the issues. For novices, supporters standing on either side might add to the safety of the exercise, but this would mean two people not participating in activity at this time.

I was reassured by my colleague Alan Rustage in his response. The truth is that safety will only come out of awareness and the consequence of ignorance can have tragic result. So please ensure that informed practice is exercise in the norm.

Yours sincerely,

DERYCK H. WILLIAMS

(Safety Officer, B.A.A.L.P.E.) 